Article

\title{
Timber Chips as the Insulation Material for Energy Saving in Prefabricated Offices
}

\author{
Yupeng Wang ${ }^{1,2, *}$ and Hiroatsu Fukuda ${ }^{3}$ \\ 1 School of Architecture and Civil Engineering, Chengdu University, Chengdu 610106, China \\ 2 School of Human Settlement and Civil Engineering, Xi'an Jiaotong University, Xi'an 710049, China \\ 3 Department of Architecture, The University of Kitakyushu, Kitakyushu 808-0135, Japan; \\ fukuda@kitakyu-u.ac.jp \\ * Correspondence: wang-yupeng@outlook.com
}

Academic Editor: Marc A. Rosen

Received: 9 May 2016; Accepted: 12 June 2016; Published: 21 June 2016

\begin{abstract}
This research demonstrates the feasibility of a roof insulation method for prefabricated offices that uses vinyl packed timber chips to reduce air conditioning loads (hereinafter referred to as AC loads) and which also improves indoor thermal comfort. The advantages of the new roof insulation method were revealed through comparing the impacts of four roof types on prefabricated offices. The AC load and indoor thermal comfort (surface temperature and air temperature) were evaluated. The disposal of scrap timber discarded from building construction projects is costing money, and is also a waste of natural resources. The assessment of a new roof insulation method with timber chips demonstrates the advanced usage of timber chips, reducing the environmental load in the building construction process. On the other hand, since prefabricated offices have lower thermal storage capacities and are less airtight than RC (reinforced concrete) or S (steel) structured buildings, the AC load consumption and indoor thermal comfort exacerbation in prefabricated offices is more serious. Especially in summer, a large amount of solar energy absorption from the roof raises the indoor air temperature and significantly increases the cooling load. This research contributes to the environmental design for prefabricated offices, and develops a method for the reuse of wood chips.
\end{abstract}

Keywords: environmental modeling; prefabricated office; AC load; thermal comfort; roof insulation

\section{Introduction}

According to the growth of the construction industry, a large amount of scrap timber accrues every year. It is estimated that more than 2.5 million tons of timber waste is generated in the United Kingdom each year [1]. In Japan, the scrap timber generated in 2010 was over seven million tons. Most of the scrap wood used for concrete forms in the construction process are discarded. Carbon fixed by wood is subsequently released into the atmosphere. Manifold reuse methods increase the recycling possibility of timber waste. This is an essential consideration for decreasing the environmental load in the building construction process. Presently, timber chip—formed mulching material and land surface paving materials are the main methods for timber reuse [1]. However, the high cost of chip bonding and forming and the limitations for land surface paving lead to inadequate timber recycling. Therefore, it is necessary to develop new timber chip reuse possibilities.

To meet the energy-saving standards for buildings in Japan [2], buildings should use high thermal insulation, including roof insulation. In cold climates such as Korea, heat energy saving with roof insulation is $71 \%$ higher than that without roof insulation [3]. There is evidence to suggest that in a hot climate such as in Riyadh, Saudi Arabia, the surface temperature with roof insulation will be $4.5^{\circ} \mathrm{C}$ cooler than that of roofs without insulation [4]. Roof insulation could reduce the heat conducted through the roof structure, and delay the transfer of heat [5]. The optimized insulation material and 
insulation location for flat roofs exposed to sunshine to reduce heat gain were analyzed in a recent study [6]. This is a significant contribution in the reduction of the cooling load. Furthermore, the analysis was carried out for several cases on two types of roof insulation (polystyrene and fiberglass) in two different locations (College Station, Texas, and Minneapolis, Minnesota). The most cost-effective thermal resistance in polystyrene in both locations was defended [7]. However, because the temporary office buildings at construction sites are rarely used in winter, very few studies are focusing on the thermal insulation in prefabricated offices.

Specifically in hot climates, cool roofs reduce urban heat islands and contribute to cooling energy consumption [8]. Taking the place of absorptive (dark in color) roofs, with reflective (light in color) roofs for all buildings, the annual electricity savings in 11 US metropolitan statistical areas will be 2.6 terawatt hours (TWh) [9]. It was also demonstrated that in typical Cairo residential buildings, using a vault roof with high albedo coating shows a decrease of $53 \%$ in discomfort hours and saves $826 \mathrm{kWh}$ during the summer season compared to conventional non-insulated flat roofs [10]. In a recent study [11], the efficiency of high-albedo roof material, hydrophilic porous materials, and green roofs were discussed.

In this research, we are focusing on building energy consumption reduction, as well as on the thermal comfort of the indoor environment with stability in temperature changes.

Normally, the roof of prefabricated offices is constructed from steel sheets and refractory investments. The indoor room air temperature changes rapidly with the amount of sunshine heat absorption, and it raises the cooling load in the daytime in summer. In the winter, high heat absorption from the sunshine can raise room temperatures and save the heating load during daytime. Cooling energy consumption mitigation is the main objective for environmental promotion. Otherwise, prefabricated offices are usually built as temporary offices or storage. A research study has indicated that besides saving energy, sustainable building materials should also be low cost, easy to apply, reusable, and non-polluting [12]. This specific insulation method for prefabricated offices should be carried out with an acceptable price and should be concise enough to be conducted.

In this paper, a simulation and field measurements were carried out to compare the environmental functions with the conduction of varied roof styles. We simulated the Air Conditioning (AC) energy consumption and indoor thermal environment of prefabricated offices with four different roof insulation methods (Roof (1): steel sheet; Roof (2): roof with reflective surface material; Roof (3): roof with insulation; Roof (4): roof with reflective surface materials and insulation). The objectives of this research were (1) to widen the usage possibility of timber chips, (2) to reduce AC energy consumption and (3) to increase the indoor thermal comfort of prefabricated offices by demonstrating the advantages of a new roof insulation style.

\section{Methodology}

We used THERB (simulation software for the thermal environment of residential buildings) for this analysis. This is dynamic simulation software that can estimate temperature, humidity, sensible temperature, and heating/cooling loads for multiple-zone buildings [13-15].

THERB has the following features:

(1) The successive transition method and the trapezoid hold function, which can adjust itself to the time-discrete domain.

(2) Dimensionless equations which are used to calculate convective heat transfer coefficients for every part of the unit.

(3) Long-wave and short-wave absorption coefficients which make it possible to simulate the net absorption of radiant heat and transmitted solar radiation.

(4) A multi-layer window model, which defines the overall transmittance, absorption and reflectance of solar radiation.

(5) A network airflow model which is used to calculate ventilation quantities. 


\subsection{Simulation Model}

We selected and simulated three prefabricated office types of normal size. The room areas were $20.88 \mathrm{~m}^{2}$ (Type 1: $4.862 \mathrm{~m} \times 4.295 \mathrm{~m} \times 2.809 \mathrm{~m}$ ), $40.20 \mathrm{~m}^{2}$ (Type 2: $9.360 \mathrm{~m} \times 4.295 \mathrm{~m} \times 2.809 \mathrm{~m}$ ) and $57.63 \mathrm{~m}^{2}$ (Type 3: $11.128 \mathrm{~m} \times 5.179 \mathrm{~m} \times 2.809 \mathrm{~m}$ ). The long sides faced south and north; the entrance was on the east exterior wall.

Figure 1 shows the plans and sections of three prefabricated office types. In this paper, we simulated roof-insulated prefabricated offices with 10-cm-thick wood chips on the roofs. The insulation effects on heating and cooling loads in the winter and summer were analyzed. Weather data for the simulation was derived from Expanded AMeDAS Weather Data [16]. We investigate the AC usage during the official working hours (from 9 a.m. to 5 p.m.).

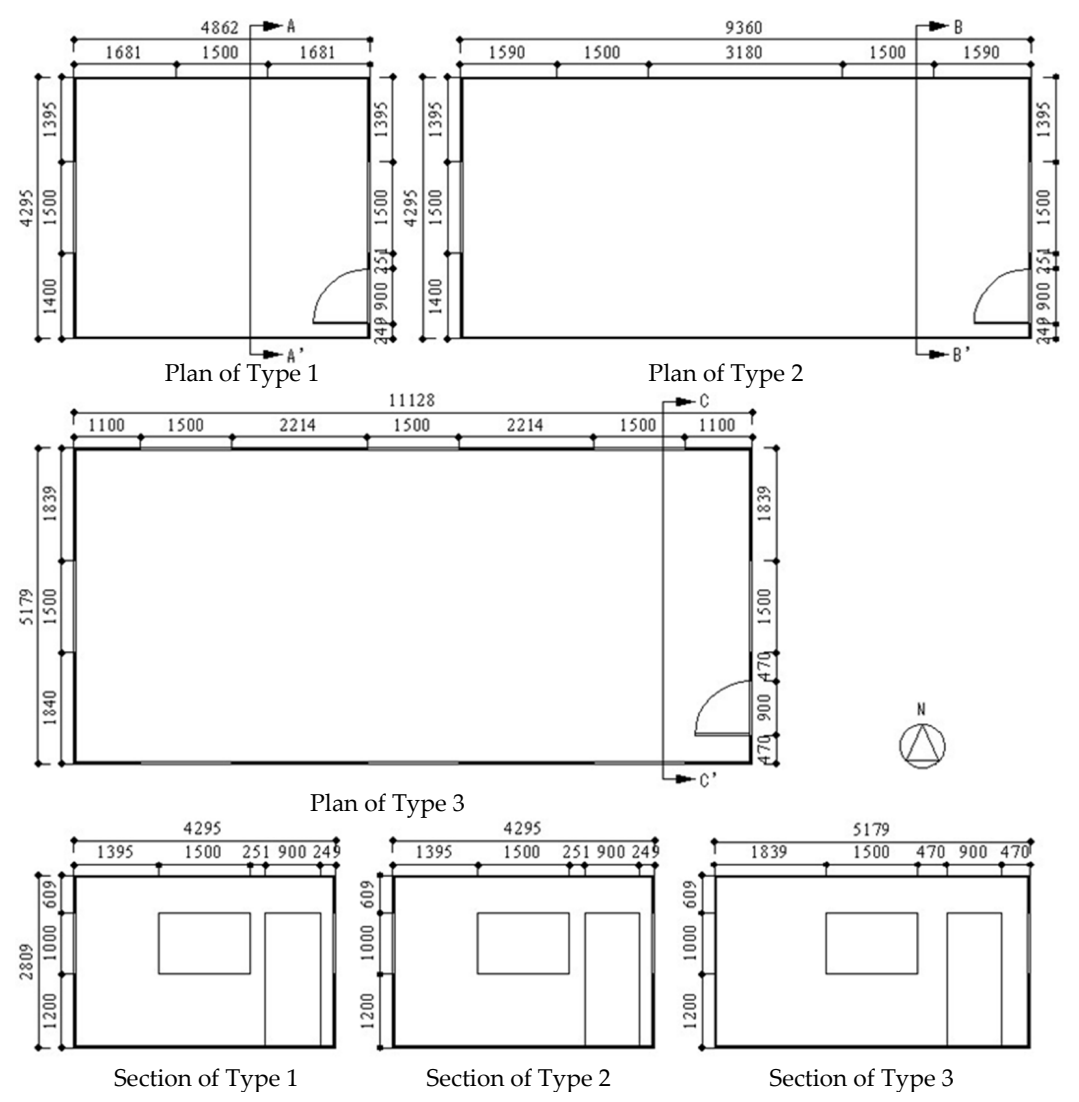

Figure 1. Three office types.

\subsection{Details of Inner Heating and Materials for Simulation}

Details of the internal heat generation, materials, solar absorption and long-wave radiation are shown in Tables 1-3 [17]. The materials of each construct component are ordered from outside to inside in Table 3.

Table 1. Details of the internal heat generation.

\begin{tabular}{ccccccc}
\hline & $\begin{array}{c}\text { Room Area } \\
\left(\mathbf{m}^{\mathbf{2}}\right)\end{array}$ & $\begin{array}{c}\text { Officer No. } \\
\text { (Person) }\end{array}$ & $\begin{array}{c}\text { Person Heat } \\
\mathbf{( W )}\end{array}$ & $\begin{array}{c}\text { Lights Heat } \\
\mathbf{( W )}\end{array}$ & $\begin{array}{c}\text { OA Heat } \\
(\mathbf{W})\end{array}$ & $\begin{array}{c}\text { Inter Heat } \\
(\mathbf{W})\end{array}$ \\
\hline Type 1 & 20.88 & 3 & 216 & 522 & 731 & 1469 \\
Type 2 & 40.20 & 5 & 360 & 1005 & 1407 & 2772 \\
Type 3 & 57.63 & 7 & 504 & 1441 & 2017 & 3962 \\
\hline \multicolumn{7}{r}{ Person Heat: 72 W/Person (Siting) }
\end{tabular}

Person Heat: $72 \mathrm{~W} /$ Person (Siting), Light Heat: $25 \mathrm{~W} / \mathrm{m}^{2}$, OA Heat: $35 \mathrm{~W} / \mathrm{m}^{2}$. 
Table 2. Details of solar absorption and long-wave radiation.

\begin{tabular}{cccccc}
\hline & & \multicolumn{2}{c}{ Inner Surface } & \multicolumn{2}{c}{ Outside Surface } \\
\cline { 3 - 6 } & & $\begin{array}{c}\text { Solar } \\
\text { Absorption }\end{array}$ & $\begin{array}{c}\text { Longwave } \\
\text { Radiation }\end{array}$ & $\begin{array}{c}\text { Solar } \\
\text { Absorption }\end{array}$ & $\begin{array}{c}\text { Longwave } \\
\text { Radiation }\end{array}$ \\
\hline Roof (1) & Steel Sheet & 0.80 & 0.90 & 0.60 & 0.20 \\
Roof (2) & Heat barrier painting & 0.80 & 0.90 & 0.08 & 0.99 \\
Roof (3) & Wooden chips & 0.80 & 0.90 & 0.80 & 0.65 \\
Roof (4) & Packed wooden chips & 0.80 & 0.90 & 0.30 & 0.90 \\
\hline & Walls & 0.60 & 0.90 & 0.40 & 0.95 \\
& Flooring & 0.65 & 0.90 & - & - \\
\hline
\end{tabular}

Table 3. Details of materials.

\begin{tabular}{|c|c|c|c|c|c|c|}
\hline \multicolumn{2}{|c|}{ Components } & Materials & $\begin{array}{c}\text { Thickness } \\
\text { (mm) }\end{array}$ & $\begin{array}{l}\text { Thermal } \\
\text { Conductivity } \\
(\mathrm{W} / \mathrm{m} \cdot \mathrm{K})\end{array}$ & $\begin{array}{c}\text { Specific of } \\
\text { Heat } \\
(\mathrm{J} / \mathrm{kg} \cdot \mathrm{K})\end{array}$ & $\begin{array}{c}\text { Specific of } \\
\text { Weight } \\
\left(\mathrm{kg} / \mathrm{m}^{3}\right)\end{array}$ \\
\hline \multirow{5}{*}{ Roof } & Steel & Steel Sheet & 0.6 & 45 & 462.4 & 8160 \\
\hline & Sheet & Refractory Investment & 5 & 0.038 & 840 & 1.2 \\
\hline & \multirow{3}{*}{ Insulated } & Wooden Chips & 100 & 0.071 & 800 & 138 \\
\hline & & Steel Sheet & 0.6 & 45 & 462.4 & 8160 \\
\hline & & Refractory Investment & 5 & 0.038 & 840 & 1.2 \\
\hline \multirow{3}{*}{\multicolumn{2}{|c|}{ Walls }} & Steel Sheet & 0.5 & 45 & 462.4 & 8160 \\
\hline & & Polurethane Foam & 30 & 0.028 & 1470 & 28 \\
\hline & & Plyboard & 10 & 0.22 & 870 & 700 \\
\hline \multicolumn{2}{|c|}{ Flooring } & Concrete & 100 & 1.6 & 840 & 2200 \\
\hline
\end{tabular}

\subsection{Details of the Materials for Actual Measurement}

Figure 2 shows the image of the wooden chips that were constructed on the building roofs for the actual measurements. White vinyl material is used to pack the wooden chips.

The coating material ATTSU-9 [Si] from Nipponpaint Industrial Coatings Co., Ltd (Tokyo, Japan) is selected for the reflective coating. ATTSU-9 [Si] is a silicone-acrylic resin coating, the service life span is seven to 10 years, and the thermal reflectivity is around 0.8 [18].

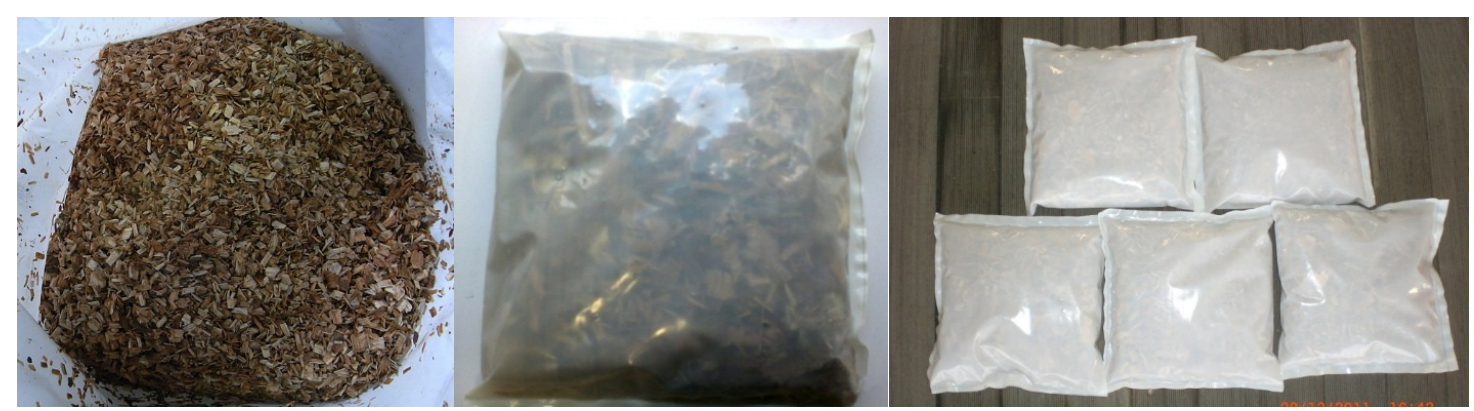

Figure 2. The pictures of wooden chips and packed wooden chips.

\section{Results of Simulation}

\subsection{Annual AC Load of Normal Prefabricated Office}

The thermal capacity of prefabricated office structure frames is obviously lower than that of Reinforced concrete (RC) or Steel (S) buildings [19-21]. Due to the specific situation of prefabricated offices, outside air temperature manifests a negative effect on the indoor environment. Without any 
insulation on the steel sheet roof, there will be significant increases in solar absorption rates, notably shifting the indoor temperature. The environmental conditions of normal prefabricated offices are revealed in this section.

Figure 3 shows the monthly AC loads of three building types. The AC loads of April and November are lower than the other months and the AC load of August is the highest month in the whole year. Comparing the three types of prefabricated offices, it is obvious that if the indoor floor area is bigger, the AC load per square meter will be lower. This could be explained by less influence from the outside air temperature on bigger rooms. The highest monthly AC load that occurs in August is reaches up to twice the lowest monthly AC load in January.

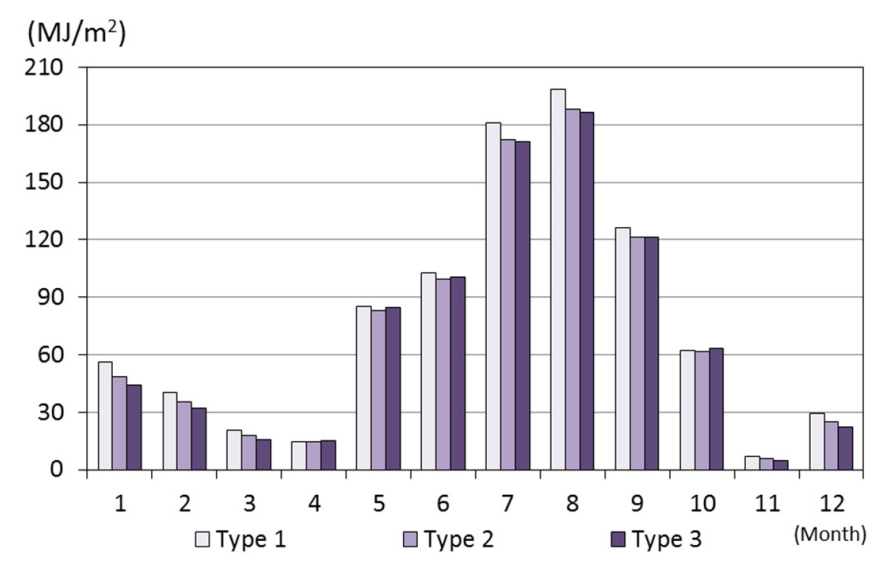

Figure 3. Monthly AC load of three building types.

Figure 4 shows the comparison between the heating load and cooling load. Normally, in RCor S-structured buildings, heating loads in the winter are about three times the cooling load in the summer [16]. Conversely, the cooling load of the steel sheet roof prefabricated offices is about five times the heating load. This is because the high heat absorption raises the indoor temperature, reducing the heating load in the winter and raising the cooling load in the summer. Consequently, in contrast to other building styles, cooling loads and the thermal comfort of prefabricated offices in the summer are critical issues for environmental design.

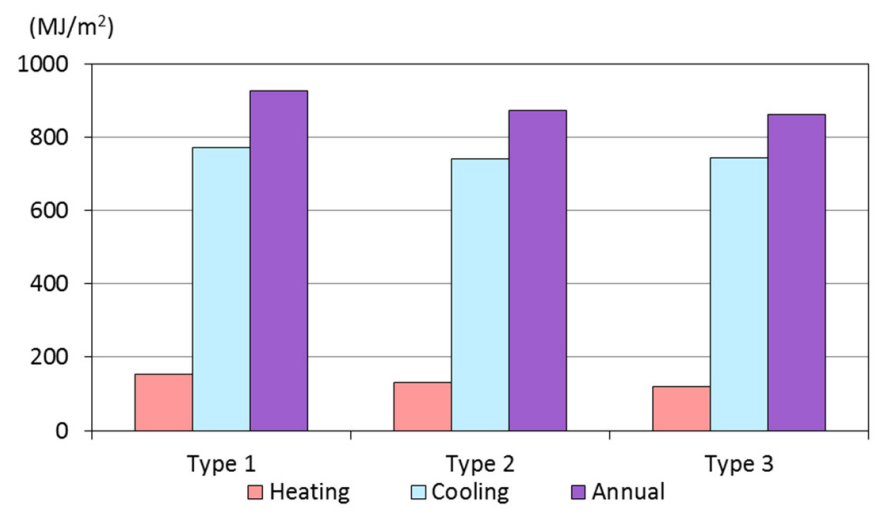

Figure 4. Comparison between heating load and cooling load.

\subsection{The Effect of Roof Insulation}

\subsubsection{About the AC Load Reduction}

Figure 5 shows the monthly comparison between steel sheet roofs and roof-insulated prefabricated offices. Similar results could be observed in the three office types. The AC loads from the steel sheet 
roof prefabricated offices were higher than those of the roof-insulated ones between April and October. In the winter the difference between the buildings with and without reflective roof pigments in March was the most significant. The ratio of increased monthly heating loads due to roof reflective pigment in March is $52.9 \%$ (Type 1) to $57.5 \%$ (Type 3). In the summer the biggest cooling load difference between buildings with and without roof reflective pigment was observed in May. The ratio of reduced monthly cooling loads due to roof reflective pigment was $81.2 \%$ (Type 1) to $83.3 \%$ (Type 3).

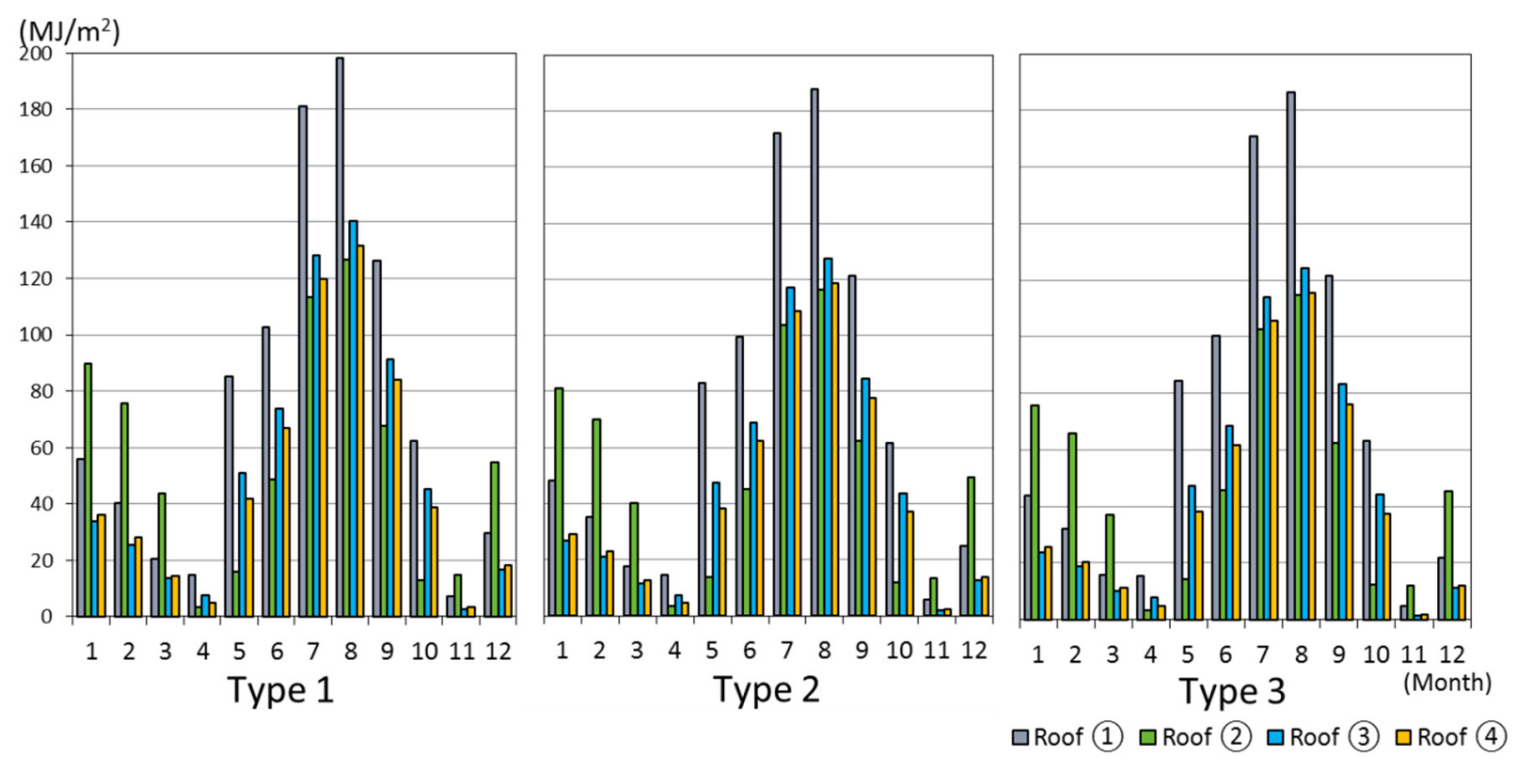

Figure 5. Monthly AC load of steel sheet roofs and roof-insulated prefabricated offices.

With roof insulation, the AC loads of prefabricated offices were reduced in the winter and summer. In the winter, the differences between buildings with and without roof insulation in January were the most significant. The ratio of decreased monthly heating loads due to roof insulation in January was $39.5 \%$ (Type 1) to $45.9 \%$ (Type 3). In the summer, the biggest cooling load difference between buildings with and without roof insulation was observed in August. The ratio of reduced monthly cooling loads due to roof insulation is $29.3 \%$ (Type 1 ) to $33.4 \%$ (Type 3 ).

With the reflective insulation roof, the AC load of prefabricated offices was lower than that of Roof 1 , both in the winter and summer. In the winter, the difference in the roof without reflective insulation is the biggest in January. The ratio of decreased monthly heating loads due to roof reflective insulation in January was $35.5 \%$ (Type 1) to $41.5 \%$ (Type 3). In summer, the biggest cooling load difference between the buildings with and without roof reflective insulation was observed in August. The ratio of reduced monthly cooling loads due to roof reflective insulation was $33.7 \%$ (Type 1) to $38.1 \%$ (Type 3).

Figure 6 shows the annual AC loads of prefabricated offices with four roof insulation types. Compared to normal prefabricated offices with Roof 1, the annual heating load will increase by $45.4 \%$ (Type 1) to $50.4 \%$ (Type 3) with Roof 2, decrease by 39.5\% (Type 1) to $44.5 \%$ (Type 3) with Roof 3 , and decrease by $34.1 \%$ (Type 1) to $39.3 \%$ (Type 3) with Roof 4 . Compared to normal prefabricated offices with Roof 1 , annual cooling loads will decrease by $50.0 \%$ (Type 1 ) to $52.5 \%$ (Type 3 ) with Roof 2 , decrease by $30.3 \%$ (Type 1 ) to $34.0 \%$ (Type 3) with Roof 3, and decrease by $36.6 \%$ (Type 1 ) to $40.7 \%$ (Type 3) with Roof 4. Compared to normal prefabricated offices with Roof 1, annual AC loads will decrease by $27.7 \%$ (Type 1 ) to $31.1 \%$ (Type 3 ) with Roof 2, decrease by $31.8 \%$ (Type 1 ) to $35.4 \%$ (Type 3 ) with Roof 3, and decrease by $36.2 \%$ (Type 1) to 40.5\% (Type 3) with Roof 4 . 


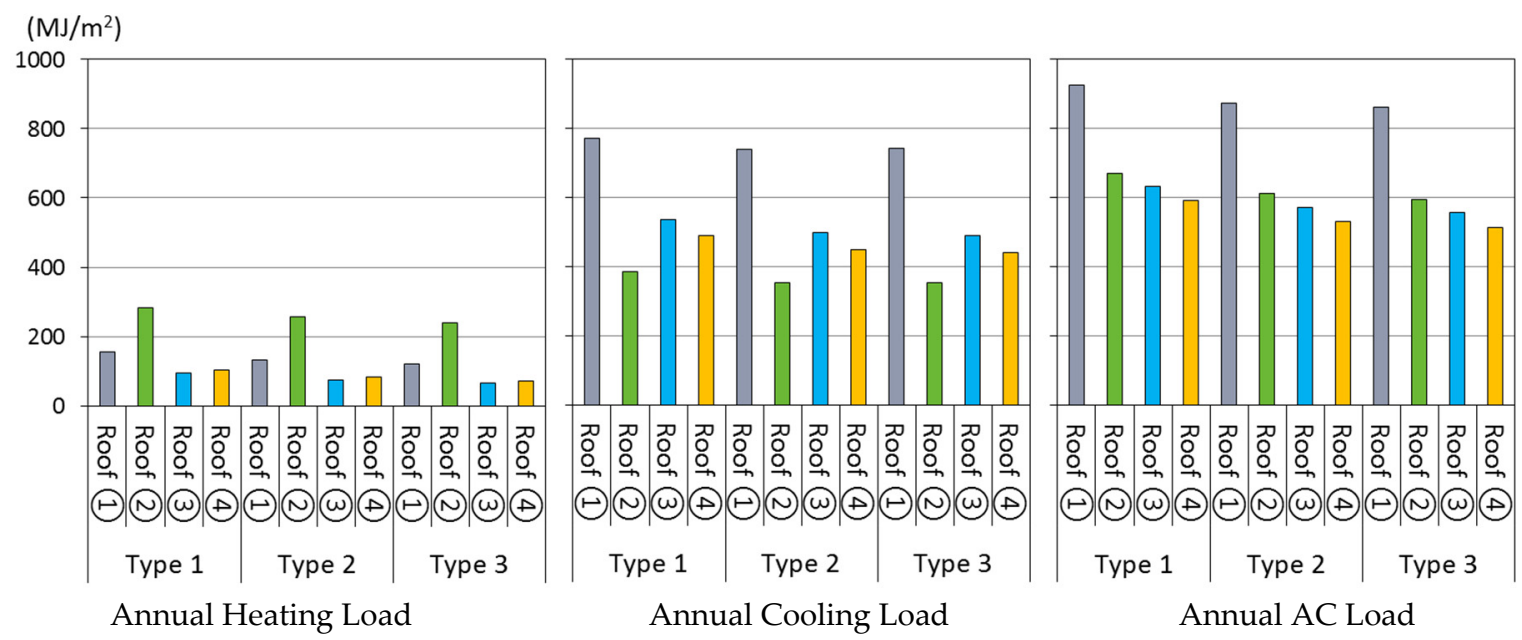

Figure 6. Annual AC load of steel sheet roofs and roof-insulated prefabricated offices.

\subsubsection{About the Thermal Comfort}

Two days in winter (5-6 February, in Figure 7) and two days in summer (15-16 August, in Figure 8) were chosen for further investigation.

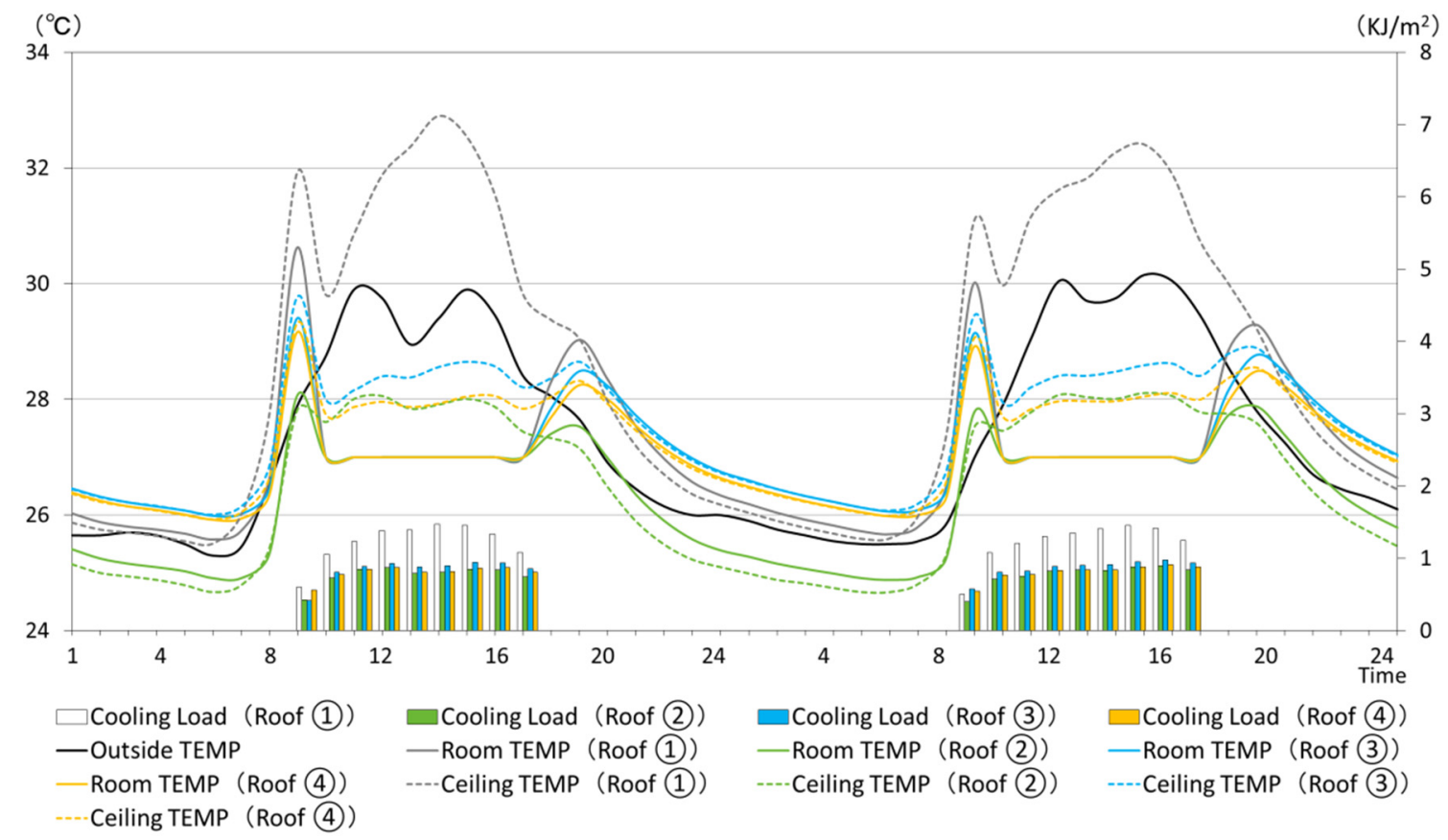

Figure 7. Relationships between ceiling surface temperatures and heating loads (5-6 February). 


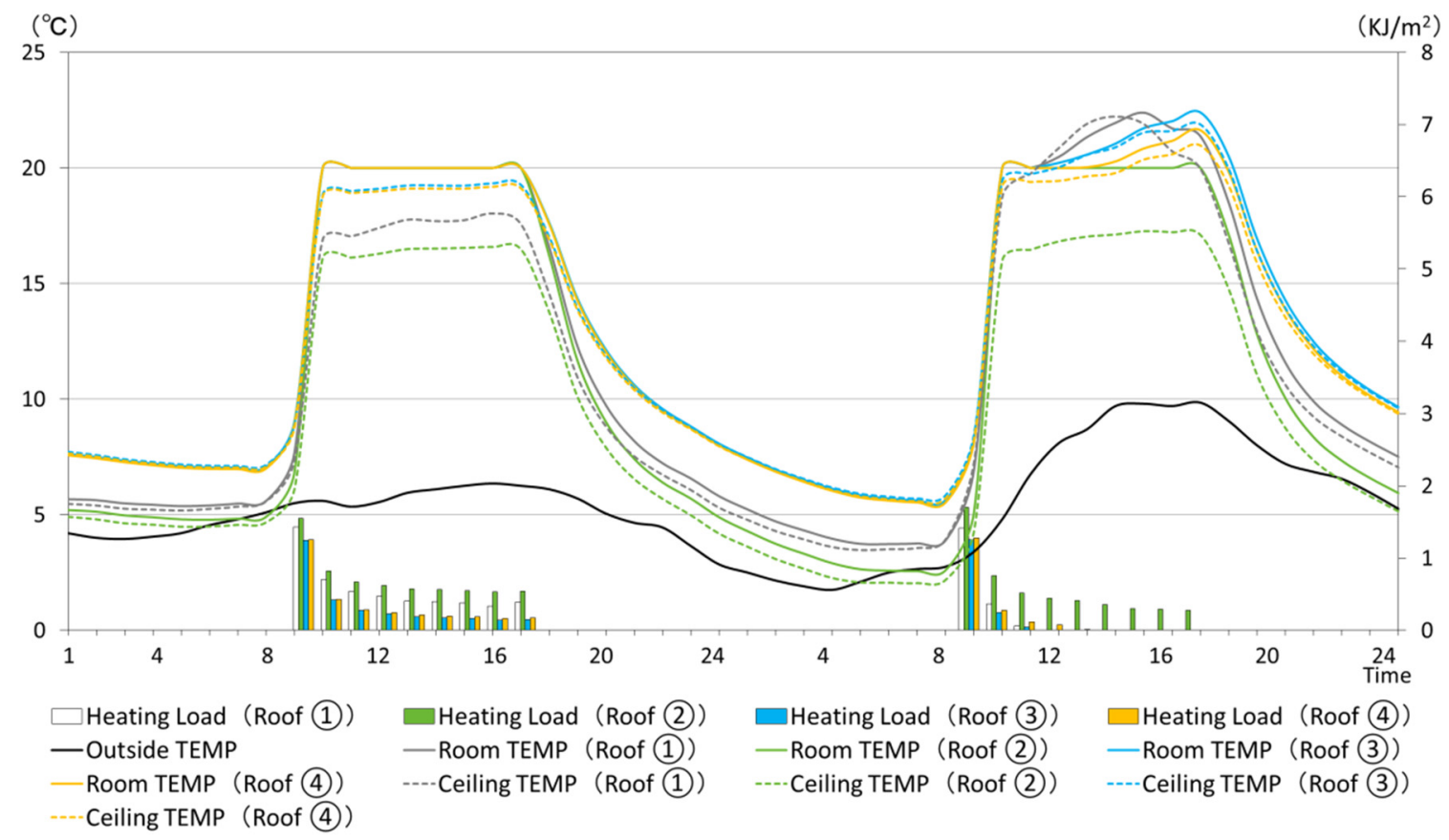

Figure 8. Relationships between the ceiling surface temperatures and the cooling loads (15-16 August).

As shown in Figure 7, in the conduction of roof (2), with the effect of the reflective coating, the roof surface temperature was decreased by more than $1{ }^{\circ} \mathrm{C}$ and the indoor air temperature was decreased by $4{ }^{\circ} \mathrm{C}$. This could be explained by the solar absorption reduction during the daytime; the significant amount of solar absorption leads to the increase of the diurnal heating energy consumption. Even in the case of a sunny day (6 February), the diurnal indoor air temperature could not reach up to $20^{\circ} \mathrm{C}$ without a heater. Meanwhile, in the conduction of roof (3), with the effect of insulation, temperatures of the roof surface and indoor air rose notably during the daytime. The temperatures increased over $20^{\circ} \mathrm{C}$ after $11 \mathrm{a}$.m. That means that indoor thermal comfort could be achieved without using the heater. However, when using roof (4) for satisfying the indoor thermal comfort, the heater had to be turned on at 1 p.m. This is because the insulation could preserve the inside heat, providing positive effects on saving heating energy, and the reflective coating reduced the solar energy absorption, contributing a negative influence on the heating energy saving. By using the reflective coating, on the cloudy day (5 February), the surface temperature with roof (4) was $0.1{ }^{\circ} \mathrm{C}$ lower than that with roof (3), and this temperature difference rose up to $1{ }^{\circ} \mathrm{C}$ on the sunny day (6 February).

During the nighttime, without using the heater in the prefabricated offices, in the office with conducting roof (1), the indoor air temperature dropped close to the outdoor air temperature. This could be considered as the predominant factor in the increase of the heat load in the morning when the heater was turned on (9 a.m.). Between 5 a.m. and 9 a.m. on 6 February, the surface temperature of roof (1) was lower than the outdoor air temperature. This could be explained by the long-wave heat release from the steel roof material. Using roof (3), the nocturnal roof surface temperature and the indoor air temperature averaged 1 to $2{ }^{\circ} \mathrm{C}$ higher than that of using roof (1). In the room with conducting roof (2), the nocturnal temperature of the roof surface and the indoor air was almost the same and more than $2{ }^{\circ} \mathrm{C}$ higher than the outdoor air temperature.

In the comparison between the heating energy consumption of various roof styles in these two days, the heating load of the prefabricated offices with roof (2) $\left(11.5 \mathrm{~kJ} / \mathrm{m}^{2}\right)$ was $40.2 \%$ higher than that of roof (1) $\left(6.9 \mathrm{~kJ} / \mathrm{m}^{2}\right)$. The heating load of prefabricated offices with roof (3) $\left(4.5 \mathrm{~kJ} / \mathrm{m}^{2}\right)$ was $34.3 \%$ lower than that of roof (4) $\left(4.9 \mathrm{~kJ} / \mathrm{m}^{2}\right)$, which was $29.0 \%$ lower than that of roof (1).

In the results of the two days in the summer (Figure 8 ), the roof surface temperatures of the prefabricated offices with roof (1) were roughly $2{ }^{\circ} \mathrm{C}$ higher than the outdoor air temperature. It was 
higher than that of the other three roof styles. The surface temperature of roof (3) was more than $2{ }^{\circ} \mathrm{C}$ lower than that of roof (2), which was about $1{ }^{\circ} \mathrm{C}$ lower than the outdoor air temperature. The surface temperature of roof (4) was about $0.5^{\circ} \mathrm{C}$ lower than that of roof (3). Cool roofs lead to a cooling load reduction and satisfying thermal comfort in summer. A notable efficiency for achieving cool roofs by using roof (4) was observed.

During the night, the roof surfaces and indoor air temperatures of prefabricated offices with roof (2) dropped under $25^{\circ} \mathrm{C}$, while those of roof (1) were about $26^{\circ} \mathrm{C}$. Indoor air temperatures using roof (3) were over $26^{\circ} \mathrm{C}$, higher than that of the other three roof types. Indoor air temperatures increased rapidly from 8 a.m., with the effects from the outdoor air and solar energy absorption. The rate of increase using roof (2) was lower than that of the other three roof types.

Comparing the cooling energy consumption between the various roof styles in these two days, the cooling load of prefabricated offices with roof (2) $\left(13.9 \mathrm{~kJ} / \mathrm{m}^{2}\right)$ was $36.8 \%$ lower than that of roof (3) $\left(30.1 \mathrm{~kJ} / \mathrm{m}^{2}\right), 30.1 \%$ lower than that of roof (4) $\left(14.5 \mathrm{~kJ} / \mathrm{m}^{2}\right)$ and $34.1 \%$ lower than that of roof (1) $\left(22.0 \mathrm{~kJ} / \mathrm{m}^{2}\right)$.

\section{Results of Actual Measurement}

Actual measurements were carried out Kitakyushu, Japan. We compared three experimental prefabricated buildings with varied roof conduction types (roof (1), roof (2), and roof (4)). The three experimental prefabricated buildings were built with the same materials and the same construction. However, AC was not conducted in the buildings. Therefore, this comparison could reflect the effects of different roof performances on the indoor air temperature without any other interference.

Figure 9 shows the comparison of the indoor air and ceiling surface temperatures on a typical winter day (7 January.). Without using the AC, the solar energy absorption from the roof and walls was the only heat source used to heat up the prefabricated building during the daytime. Roof insulation reduced the solar heat conduction. This is the reason that the ceiling temperature with roof (4) was lower than that of buildings with roofs (1) and (2). This phenomenon was also observed in the daytime of 6 February in the simulation (Figure 6). Meanwhile, at nighttime, insulated roofs helped to maintain the indoor temperature. This leads to a higher indoor air temperature with roof (4) than with roof (1) and (2).

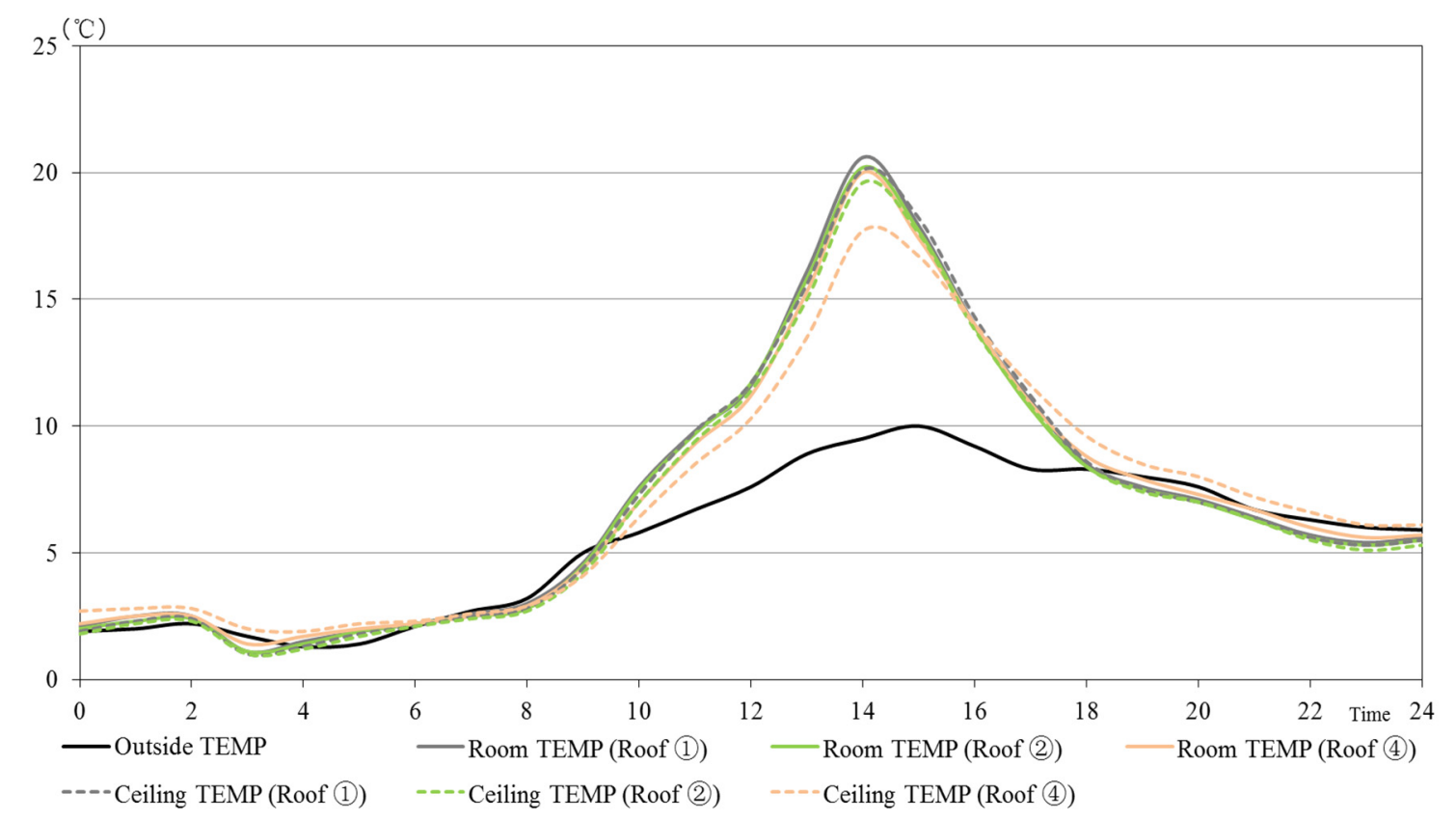

Figure 9. Comparison of indoor air and ceiling surface temperatures (measured at 7 January 2012). 
Figure 10 shows the comparison results on a typical summer day (11 August). The indoor air temperature with roof (2) was higher than that with roof (4) in the morning, and it turned out to be the opposite after 1 p.m. The indoor air temperature of prefabricated buildings with roof (4) was higher than that of roof (2) until the night. This could also explain why roof (4) had a higher cooling load than roof (2) as observed in Figure 8.

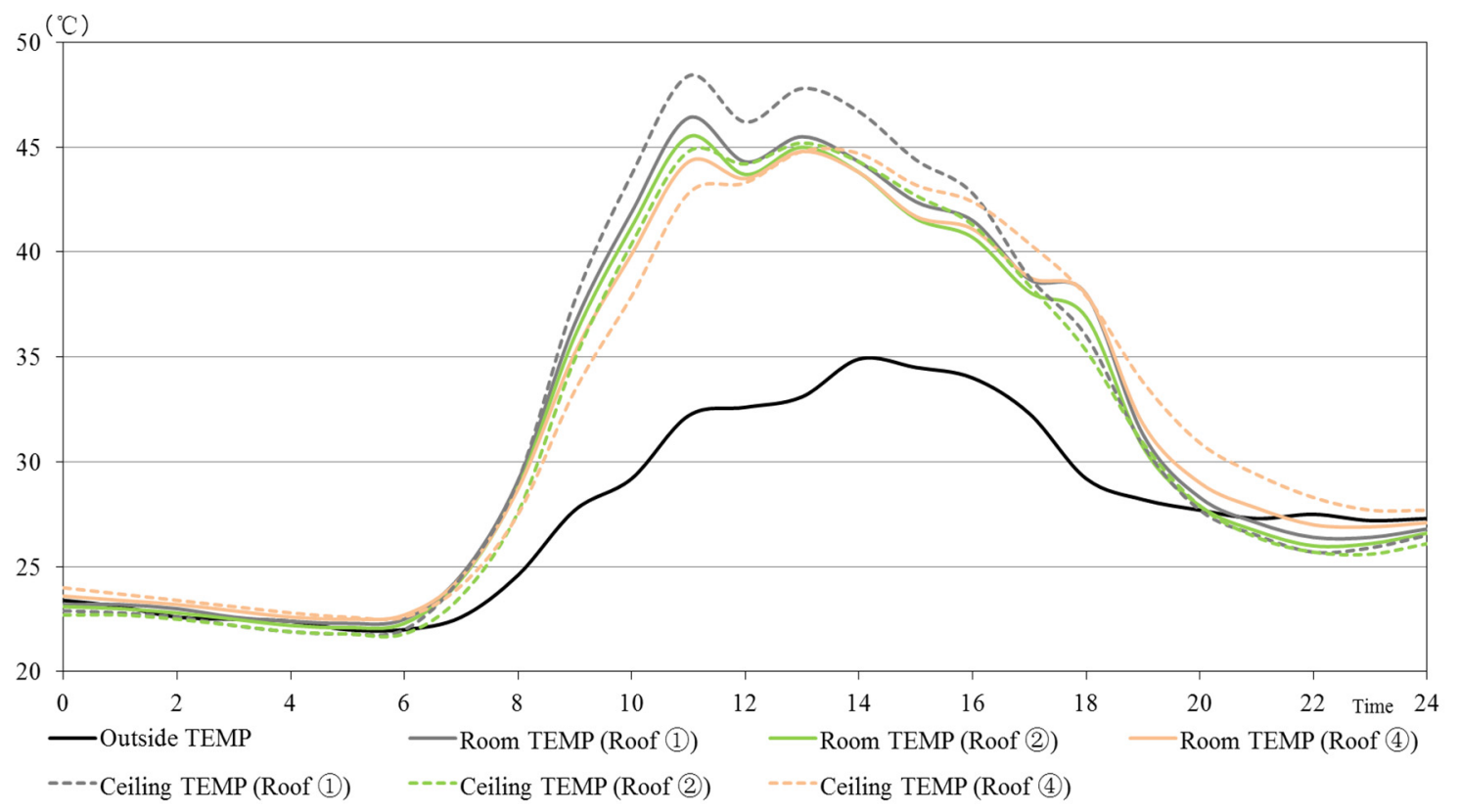

Figure 10. Comparison of indoor air and ceiling surface temperature (measured at 11 August 2012).

\section{Conclusions}

As the result of this simulation study using the reflective pigment conducted roof, the annual AC load was reduced by $29.6 \%$ with roof insulation and the annual AC load was reduced by $33.9 \%$, while the white vinyl packed timber chip insulation on the roof reduced $40.5 \%$ of annual the AC load. A distinct advantage of energy saving with the new roof insulation style was demonstrated.

(1) In prefabricated offices with reflective-coated roofs (roof (2)), the solar energy absorption was significantly reduced. During the summer, the diurnal indoor air temperature increase was mitigated. Because of the small heat capacity without insulation, the indoor heat could be readily cooled down. Conversely, in winter, because of the significant impacts from the outdoor air and low solar energy absorption, it took more time and energy to heat up the whole office.

(2) In prefabricated offices with insulated roofs (roof (3)), temperature differences between the indoor air and the interior roof surface were smaller than those of the steel sheet roof prefabricated offices, resulting in an extreme annual AC load reduction of $84.8 \mathrm{kWh} / \mathrm{m}^{2}$ (roof (3)).

(3) With the new roof style that we provided (roof (4)), the heating load in winter was slightly higher than it was in the insulated roof (roof (3) prefabricated offices and the cooling load in the summer was obviously low. The annual AC load reduction was $10.9 \%$ (roof (3)) compared to the reflective-coated roof (roof (2)) which was 7.8\% (roof (3)) lower than that of the insulated roof (roof (3)) prefabricated offices.

In this paper, we provided a new roof insulation style with vinyl packed roof insulation using wood chips and compared and discussed the AC load consumption characteristics and indoor thermal comfort in prefabricated offices with other three roof styles. As a new energy-saving contracture method, it is straightforward to conduct and has a low monetary cost. Most of all, this is a new possibility for reusing disposed timber that has been discarded from the building construction industry. 
We suggest the use of roof insulation on prefabricated offices to reduce the effect of high solar heat absorption and verify the advantage of this new roof insulation method. Overall, this research contributes to prefabricated office environmental design and the development of the possibility of reusing wood chips.

Additionally, this research demonstrated the possibility and the environmental performance of roof insulation using vinyl packed wood chips though we did not investigate the economic efficiency. The economic cost of this new roof insulation style includes the cost of wood chipping, the manpower for packing and conducting, and the transportation expenses. The balance between the environmental performance and the economic efficiency is a critical issue for the popularizing of new technology, and with these considerations, this should be discussed in the future research.

Author Contributions: Yupeng Wang and Hiroatsu Fukuda conceived and designed the experiments; Yupeng Wang and Hiroatsu Fukuda performed the experiments; Yupeng Wang and Hiroatsu Fukuda analyzed the data; Yupeng Wang and Hiroatsu Fukuda contributed analysis tools; Yupeng Wang wrote the paper.

Conflicts of Interest: The authors declare no conflict of interest.

\section{References}

1. Senaratne, S.; Gerace, D.; Mirza, O.; Tam, V.W.Y. The costs and benefits of combining recycled aggregate with steel fibres as a sustainable, structural material. J. Cleaner Prod. 2016, 112, 2318-2327. [CrossRef]

2. Institute for Building Environment and Energy Conservation. Explanation of the Energy-Saving Standards for Houses 2002; Institute for Building Environment and Energy Conservation: Tokyo, Japan, 2002.

3. Mousa, M.S.; Akash, B.A. Some prospects of energy saving in buildings. Energ. Convers. Manag. 2001, 42, 1307-1315.

4. Salmaan, C.; David, H.; Cripps, A.; Knott, D. BioTRIZ suggests radiative cooling of buildings can be done passively by changing the structure of roof insulation to let longwave infrared pass. J. Biol. Educ. 2008, 5, $55-66$.

5. Ramamurthy, P.; Sun, T.; Rule, K.; Bou-Zeid, E. The joint influence of albedo and insulation on roof performance: An observational study. Energ. Build. 2015, 93, 249-258. [CrossRef]

6. Shaik, S.; Talanki, A.B.P.S. Optimizing the position of insulating materials in flat roofs exposed to sunshine to gain minimum heat into buildings under periodic heat transfer conditions. Environ. Sci. Pollut. Res. 2015, 23, 1-11. [CrossRef] [PubMed]

7. Al-Sallal, K.A. Comparison between polystyrene and fiberglass roof insulation in warm and cold climates. Renew. Energ. 2003, 28, 603-611. [CrossRef]

8. Akbari, H.; Levinson, R.; Miller, W.; Berdahl, P. Cool Colored Roofs to Save Energy and Improve Air Quality; Ernest Orlando Lawrence Berkeley National Laboratory: Berkeley, CA, USA, 2005.

9. Akbari, H.; Cartalis, C.; Kolokotsa, D.; Muscio, A.; Pisello, A.L.; Rossi, F.; Santamouris, M.; Synnefa, A.; Wong, N.H.; Zinzi, M. Local climate change and urban heat island mitigation techniques—the state of the art. J. Civ. Eng. Manag. 2016, 22, 1-16. [CrossRef]

10. Dabaieh, M.; Wanas, O.; Hegazy, M.A.; Johansson, E. Reducing cooling demands in a hot dry climate: A simulation study for non-insulated passive cool roof thermal performance in residential buildings. Energ. Build. 2015, 89, 142-152. [CrossRef]

11. Pacheco-Torgal, F., Labrincha, J., Cabeza, L., Granqvist, C.G., Eds.; Eco-efficient Materials for Mitigating Building Cooling Needs: Design, Properties and Applications, 1st ed.; Woodhead Publishing: Cambridge, UK; Waltham, MA, USA; Kidlington, UK, 2015.

12. Joseph, P.; Tretsiakova-McNally, S. Sustainable Non-Metallic Building Materials. Sustainability 2010, 2, 400-427. [CrossRef]

13. Kuma, Y.; Fukuda, H.; Ozaki, A. Performance evaluation of residences by dynamic simulation: heat load based on changing the location, plan and specification of residences. J. Asian. Architect. Build. Eng. 2007, 6, 183-188. [CrossRef]

14. Ozaki, A.; Watanabe, T.; Hayashi, T.; Ryu, Y. Systematic analysis on combined heat and water transfer through porous materials based on thermodynamic energy. Energ. Build. 2001, 33, 341-350. [CrossRef] 
15. Ozaki, A.; Tsujimaru, T. Prediction of hygrothermal environment of buildings based upon combined simulation of heat and moisture transfer and airflow. In Proceedings of the Ninth International IBPSA Conference, Montréal, AL, Canada, 15-18 August 2005.

16. Architectural Institute of Japan. Expanded AMeDAS Weather Data (1981-2000); Architectural Institute of Japan: Tokyo, Japan, 2005.

17. Morikita Publishing Co., Ltd. Architectural Environment Engineering 1996; Morikita Publishing Co., Ltd: Tokyo, Japan, 1996.

18. Japan Federation of Construction Contractors. Survey Report on the Properties of Building Materials; Japan Federation of Construction Contractors: Tokyo, Japan, 2014.

19. Tsukiyama, Y.; Sunaga, N.; Suzuki, A.; Fukazawa, T.; Chiba, Y. Study on thermal storage characteristics of AAC floor panels using an actual test rooms. Am. J. Environ. Eng. 2010, 75, 149-156. [CrossRef]

20. Wang, Y.; Fukuda, H.; Kuma, Y.; Ozaki, A. Study of Air-conditioning load: Comparison of steel and RC residence units. J. Asian. Architect. Build. Eng. 2010, 9, 571-576. [CrossRef]

21. Wang, Y.; Fukuda, H.; Ozaki, A. Simulation study on the effect of insulation on interior structural parts of super high-rise residences. Am. J. Environ. Eng. 2011, 76, 999-1008. [CrossRef]

(C) 2016 by the authors; licensee MDPI, Basel, Switzerland. This article is an open access article distributed under the terms and conditions of the Creative Commons Attribution (CC-BY) license (http://creativecommons.org/licenses/by/4.0/). 